\title{
SHARING EXPERTISE: A PROMISE KEPT
}

\author{
B. Braun Medical Ltd. \\ infohu@bbraun.com
}

Having been founded in 1839, B. Braun is now one of the leading health care companies of the world. The enterprise owned by a German family is providing every sector of the health care system with its products and services in 50 countries of the world, employing 38000 colleagues.

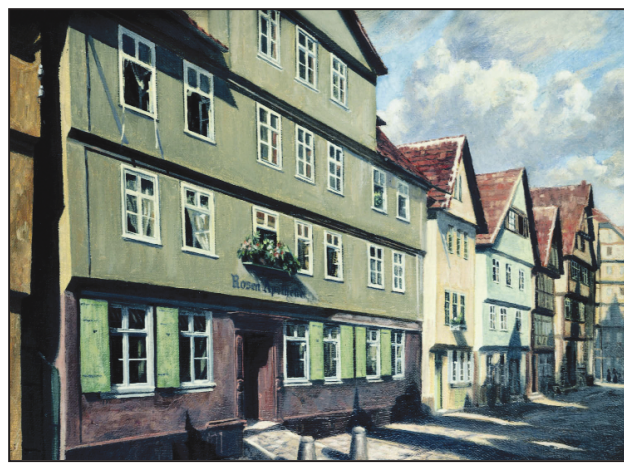

1839

Melsungen-centred B. Braun has been present in Hungary with its products and services for more than 30 years. B. Braun group is now represented by two subsidiaries: B. Braun Medical Ltd. producing, selling and developing products and B. Braun Avitum Hungary CPLC ensuring dialysis treatment for close to $40 \%$ of Hungarian patients with renal insufficiency. The group with these two companies and their 1400 employees plays one of the most important role of Hungarian health care market.

B. Braun Medical Kft. can be divided into three areas: production, sales and development. The factory in Gyöngyös employing close to 700 people produces infusion and transfusion sets and catheters - altogether about 50 million products a year. Sales activity is carried out in three different divisions: Aesculap, Hospital Care and OPM (Out Patient Market). B. Braun supplies the global healthcare market with products for anaesthesia, intensive medicine, cardiology, extra corporeal blood treatment and surgery, as well as services for hospitals, general practitioners and the homecare sector. Plastic, disposable medical instruments, surgical suture materials, infusion solutions and disinfectants, bandages and stoma therapeutic systems can be found among the broad range of the company's products widely used also in Hungarian health care. All three divisions work in five sales regions in Hungary on the basis of the market demand.

Aesculap Division focuses on products and services for core processes in surgery. The product range includes among other items surgical instruments for open or minimally invasive approaches, implants (e.g. for orthopaedics, neurosurgery and spinal surgery), surgical sutures, sterile container, storage, motor and navigation systems as well as products for cardiology. The division also actively exchanges knowledge through its international service network and its numerous continuing education programs at the Aesculap Academy.

B. Braun is proud to have remained a family business over the past 170 years. On $23^{\text {rd }}$ June 1839 Julius Wilhelm Braun purchased the Rosen-Apotheke, a pharmacy in Melsungen, Germany and expanded it by a mail-order business for local herbs. In 1864 Bernhard Braun, the eldest son of Julius Wilhelm 
Braun took over the pharmacy and he began producing pharmaceutical products like migraine sticks and plasters. The foundation of Aesculap dates back to 1867 when Gottfried Jetter, a qualified cutler began manufacturing surgical instruments in Tuttlingen, Germany. In the same year B. Braun was divided into Department A (pharmacy) and Department B (pharmaceutical products). Bernhard Braun registered the company name in the commercial register as "B. Braun".

In 1889 the first branch of Aesculap was opened in Berlin, then in 1893 the company ventured into international territory with a branch in New York, London, Paris, Constantinople, Buenos Aires and Tokyo are added shortly afterwards. In 1895 the family business was transformed into a stock corporation. The construction of a new factory designed by the famous industrial architect Philipp Jacob Manz started in 1898, and in the next year Aesculap was registered as a trademark.

In 1908 B. Braun first produced absorbable suture material (catgut) from sheep intestines using Kuhn's method. In 1914 the newly formed medico-mechanical workshop began manufacturing splints for surgery, simple extensions and blood pressure measuring devices. B. Braun set up its own company health insurance fund in 1923. Two years later the company established its first foreign production facilities in Milan, Italy. In 1930 B. Braun developed the modified Tyrode's solution Sterofundin ${ }^{\circledR}$, the basis for all later infusion solutions. In 1935 the production of Synthofil A, a non-absorbable synthetic suture material began. In the same year the first surgical electric motor was invented at Aesculap.

B. Braun had some 500 employees in its centennial year, 1939. Ten years later SupramidBraun, a surgical suture material made from



1908

nylon, was developed and in 1951 the first injection pump for continuous infusions, predecessor of the Perfusor ${ }^{\circledR}$ appeared. In 1953 the production of infusion devices made of glass and three years later the ones made of plastic - so-called "infusors" - began.

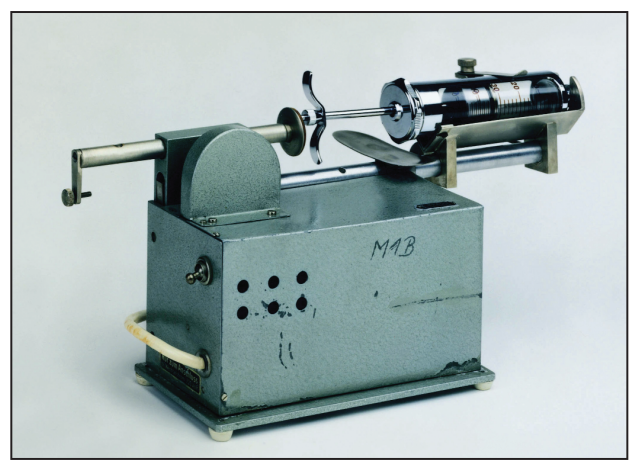

1951

The Braunüle ${ }^{\circledR}$, the first one-piece cannula for continuous infusions was released for sale in 1969. Lipofundin ${ }^{\circledR}$, the first infusable fat emulsion, was also launched on the market 


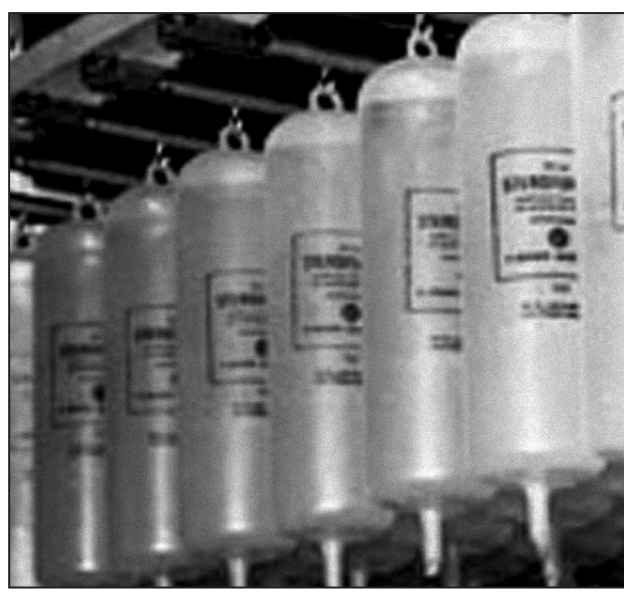

1956

that year. In 1967 the first surgical pneumatic motor was invented at the company. At the beginning of the 1970s Aesculap responded to the need for new specialized disciplines in the field of surgery and developed new products for cardiovascular surgery, arthroscopy and microsurgery, as well as hip joint prostheses.

The history of the two companies started to converge in 1976, when B. Braun acquired a controlling interest in Aesculap AG. In 1995 the Aesculap Academy and the Aesculapium in Tuttlingen, Germany were dedicated.

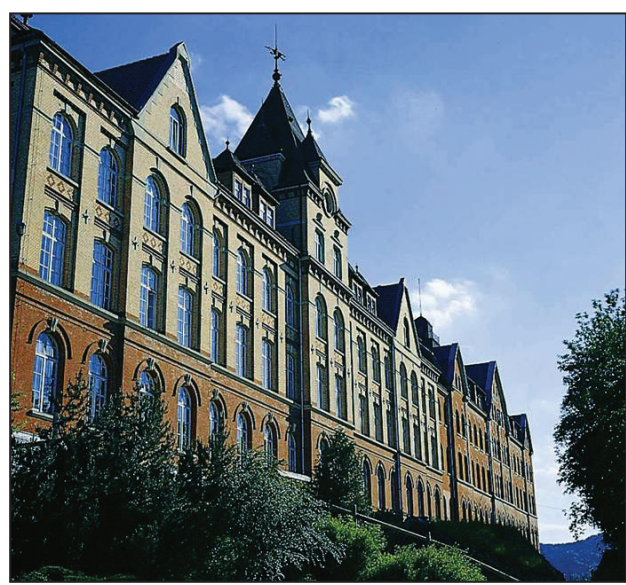

1976

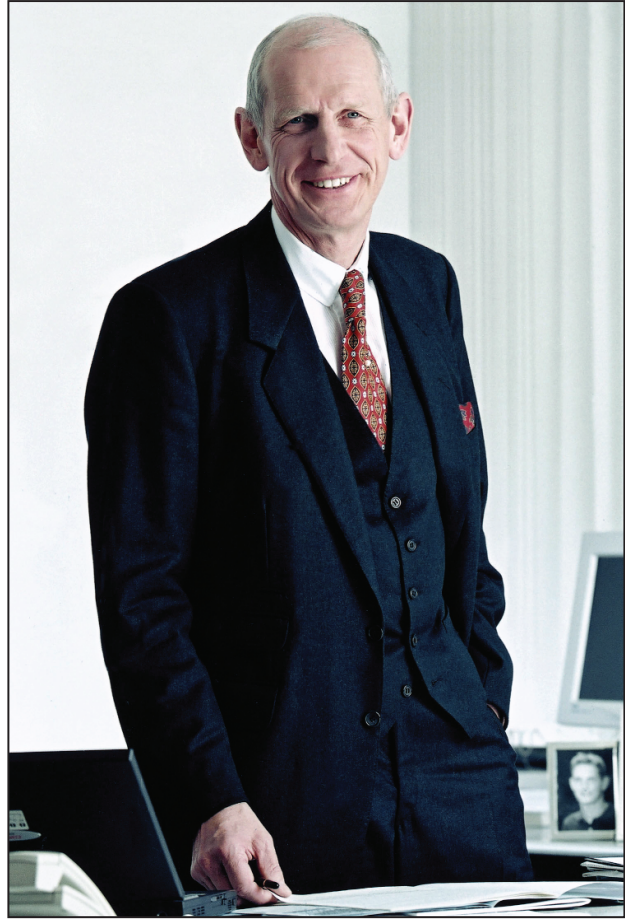

1977

Three years later Aesculap AG \& Co KG was incorporated into the B. Braun Group as the Aesculap Division. In 2001 Ludwig Georg Braun, Chairman of the Board of Management was elected President of the DIHK (Association of German Chambers of Industry and Commerce). The company decided to build a new pharmaceutical factory in Melsungen and a Benchmark Factory in Tuttlingen for the production of implants. In 2004 the groundbreaking for two new factories in China (for infusion solutions and surgical instruments) started and in the next year the L.I.F.E. infusion solutions factory (Leading Infusion Factory Europe) was officially opened.

The Hungarian branch of B. Braun has been serving health care in Hungary since 1991, when its two subsidiaries were founded and the factory in Gyöngyös was dedicated. Since 




1995

1995 the plant has been performing its activities in accordance with the strict regulations of ISO quality management system and since 2003 it has owned an FDA certificate. In 2007 Aesculap Academy opened in Budapest in order to ensure a continuous dialogue between different medical areas and the training of Hungarian health care professionals. B. Braun in Hungary started its corporate social responsibility programme, "B. Braun for Children" in 2006 and has supported numerous important social aims ever since.

"Sharing Expertise" is not only the slogan of B. Braun but also a promise the company makes to the customers and colleagues in order to share knowledge and experience through mutual dialogues and serve the health care sector applying this knowledge as efficiently as possible. Accordingly, the three core values of the group are innovation, efficiency and sustainability. Sharing Expertise means sharing medical know-how and skills in a process of interaction with business partners for the advancement of healthcare and it also means the effective deployment and systematic expansion of that expertise. Through dialogue with those who are using B. Braun's products on a daily basis, the company is continually gaining new knowledge which it incorporates into product development. This way, the company contributes with innovative products and services to optimizing working procedures in hospitals and medical practices all over the world and improving safety - for patients, doctors and nursing staff. "Sharing Expertise" is what employees at B. Braun continuously keep in mind.

\section{B. Braun Medical Ltd.}

H-1023 Budapest, Felhévízi u. 5.

Tel.: (+36) 1 346-9700 